\title{
Syringic Acid Metabolism by Some White-rot, Soft-rot and Brown-rot Fungi
}

\author{
By KARL-ERIK ERIKSSON, * JUGAL KISHORE GUPTA, † \\ ATSUMI NISHIDA‡ AND MALA RAO§
}

Swedish Forest Products Research Laboratory, Box 5604, S-114 86 Stockholm, Sweden

(Received 27 January 1984; revised 2 April 1984)

\begin{abstract}
The pathways for syringic acid metabolism have been studied in detail for the white-rot fungus Sporotrichum pulverulentum and a reaction sequence proposed. According to identified metabolites the following reactions occur: reduction of the carboxyl group; hydroxylation and simultaneous decarboxylation; demethylation; and methylation of the $p$-hydroxyl group. In the two soft-rot fungi Petriellidium boydii and Phialophora mutabilis rapid metabolism of syringic acid was observed and the medium was depleted of the acid within $12 \mathrm{~h}$. The formation of 3,4,5trimethoxybenzoic acid indicates an ability within the soft-rot fungi also to methylate the phydroxyl group. The two brown-rot fungi Daedalea quercina and Fomes pinicola were poor metabolizers of syringic acid. However, demethylation was observed with $F$. pinicola and an unidentified product appeared in the culture solution of $D$. quercina.
\end{abstract}

\section{INTRODUCTION}

Softwood lignins predominantly consist of guaiacyl groups while the hardwood lignins are known to contain both guaiacyl and syringyl type structures (Nimz, 1974: Adler, 1977). Henderson (1963) demonstrated the formation of syringic and vanillic acids from birch sawdust and only vanillic acid from spruce sawdust after attack by the two white-rot fungi Polystictus versicolor and Trametes pini.

Considerable information is available on the metabolism of vanillic acid by fungi (Ander et al., 1980, 1983, 1984; Buswell et al., 1979, 1982; Kirk \& Lorenz, 1973), while relatively little is known about the metabolism of syringic acid, especially by fungi. Sparnins \& Dagley (1975) reported that $P$ seudomonas putida degraded syringic acid via $3-O$-methylgallic acid. Kirk \& Lorenz (1974) found that the white-rot fungus Polyporus dichrous did not degrade syringic acid although this organism is a degrader of hardwood lignins. Haider \& Trojanowski (1975) demonstrated the release of $2.6-3.8 \%{ }^{1+} \mathrm{CO}_{2}$ in $9 \mathrm{~d}$ from both of the labelled methoxyl carbons of syringic acid and the release of $78-84 \%{ }^{1+} \mathrm{CO}_{2}$ from ${ }^{14} \mathrm{C}$-carboxyl-labelled syringic acid when added to cultures of two white-rot fungi. Four soft-rot fungi studied in the same investigation showed considerable variations in ${ }^{14} \mathrm{CO}_{2}$-evolution; $0.2-26 \%$ from syringic acid $-\mathrm{O}^{14} \mathrm{CH}_{3}$ carbon, $2 \cdot 4-87 \%$ from the carboxyl-labelled carbon.

In this communication we present a survey of the metabolism of syringic acid by four whiterot fungi (two low and two high producers of phenol oxidases; Ander \& Eriksson, 1977), two soft-rot and two brown-rot fungi.

\section{METHODS}

Organisms. The following organisms were used in this study.

(I) White-rot fungi - low producers of phenol oxidases: Sporotrichum pulverulentum Nov. (ATCC 32629):

† Present address: Dept of Microbiology, Panjab University, Chandigarh, India.

+ Present address: Forestry and Forest Products Research Institute, Tsukuba, Japan.

Present address: Biochemistry Dept, National Chemical Laboratory, Poona, India. 
Phanerochaete sp. L-1. White-rot fungi - high producers of phenol oxidases: Pycnoporus cinnabarinus (Jacq. ex Fr.) Karst A-360; Pleurotus ostreatus (Jacq. ex Fr.) Kummer IPB no. 53.

(II) Soft-rot fungi: Petriellidium boydii (Shear) Maltoch SP 31-4; Phialophora mulabilis (van Beyma) ScholSchwarz 203-E-15-y-1.

(III) Brown-rot fungi: Daedalea quercina (L. ex Fr.) 69346; Fomes pinicola (Sw. ex Fr.) Karst. B.H.

Pleurotus ostreatus was obtained from Dr R. Sopko, North Carolina State University, USA, and the rest of the organisms were kindly provided by Dr Thomas Nilsson. The Swedish University of Agricultural Sciences, Uppsala, Sweden.

Chemicals. Most of the chemicals used were commercially available. Syringic acid, 3,4,5-trimethoxybenzoic acid, 3,4,5-trimethoxybenzyl alcohol and veratryl alcohol were from Ega-Chemie, 7924 Steinheim/Albuch. FRG. 3-O-Methylgallic acid was kindly provided by $\mathrm{Dr}$ John A. Buswell of Paisley College, UK. Syringol (2,6dimethoxyphenol) was obtained from Eastman Organic Chemicals. $\mathrm{N}$-O-Bis(trimethylsilyl)trifluoroacetamide (BSTFA) was from Pierce Chemical Co., Rockford, III., USA. 3,4,5-Trimethoxybenzoic acid or the alcohol are hereafter called trimethoxybenzoic acid (alcohol).

Media and culture conditions. The basal medium used was a modified Norkrans medium (Eriksson \& Pettersson, 1975) which was further modified in order to give good growth of all the fungi studied. Asparagine $\left(1 \cdot 15 \mathrm{~g} 1^{-1}\right)$ was substituted for ammonium hydrogen phosphate in all cases. The following carbon sources (in addition to syringic acid) were used for the different groups : soft-rot fungi. $1 \%$ cellulose: white-rot fungi, $1 \%$ cellulose with or without $0.25^{\circ}$ cellobiose; brown-rot fungi, $1 \%$ cellulose with $0.25^{\circ}$, cellobiose. For all fungi the yeast extract concentration was $0.01^{\circ}$.

Disintegrated mycelium was used as inoculum in all cases except for $S$. pulverulentum where a spore suspension was used. The final spore concentration in the flasks was $1 \times 10^{6}$ spores $\mathrm{ml}^{-1}$. To obtain sufficient inoculum the fungi were grown for $1-2$ weeks in stationary culture in $250 \mathrm{ml}$ Erlenmeyer flasks on the above medium with $1 \%$ glucose as carbon source. The mycelium obtained as inoculum was suspended in a small volume of sterile distilled water and disintegrated with glass beads on a reciprocating shaker. The suspension thus obtained was uniformly inoculated into $300 \mathrm{ml}$ medium in $1-1$ flasks and cultivated under shaking conditions at $28 \pm 1{ }^{\circ} \mathrm{C}$. The syringic acid was dissolved in $0.2 \mathrm{M}-\mathrm{NaOH}$, filter sterilized, and added to the media when a certain amount of growth was obtained. The following times (after inoculation of the media) of addition of syringic acid were used: $S$. pulterulentum, Petriellidium boydii and Phialophora mutabilis, $47 \mathrm{~h}$; Phanerochaete sp. L-1, $68 \mathrm{~h}$; Pycnoporus cinnabarinus, $72 \mathrm{~h}$; Pleurotus ostreatus, $69 \mathrm{~h} ; F$. pinicola, $120 \mathrm{~h} ; D$. quercino, $120 \mathrm{~h}$. A final concentration of $1 \mathrm{mM}-$ syringic acid was used in all media.

Gas chromatography and mass spectrometry. After cultivation the fungal mycelium was filtered off and the culture solution was concentrated by film evaporation at $40^{\circ} \mathrm{C}$. The concentrated culture fluid was then extracted by ethyl acetate and processed for GC-MS analysis by silylation and addition of syringol as standard (Gupta ef al., 1981).

A rough estimate of the disappearance of syringic acid in the culture media was monitored by measuring the decrease in absorbance at $262 \mathrm{~nm}$. where syringic acid has a sharp peak at $\mathrm{pH} 7 \cdot 0$.

\section{RESULTS}

\section{Syringic acid metabolism by the four white-rot fungi}

Low phenol oxidase producers. The fungi Sporotrichum pulverulentum and Phanerochaete sp. L-1 were studied both with and without cellobiose $(0.25 \%)$ in the cellulose/syringic acid medium. The former rapidly metabolized syringic acid ( $\mathrm{I}$ in Fig. 2) with the appearance of a pinkish coloration. A bout $40 \mathrm{~h}$ after the addition of syringic acid only about $10 \%$ of the acid was left in the medium (Fig. I a). Trimethoxybenzoic acid, trimethoxybenzyl alcohol and veratryl alcohol (II, III, VI in Fig. 2) were found to be the prominent metabolites identified both by GC-MS and by reference compounds in the GC runs (Figs 2 and 3). 3-O-Methylgallic acid (V) was found in small quantities. Two other major peaks $(X, Y)$ appear to be some kind of ring cleavage products as indicated by MS but it has not been possible to identify these compounds. An isomer of syringic acid, 3-hydroxy-4,5-dimethoxybenzoic acid (IV), was also formed. In cultures with cellobiose the quantity of trimethoxybenzyl alcohol (III) was proportionately much higher than that of other metabolites. None of the above reported products were found in cultures grown without syringic acid.

In Table 1 a quantitative presentation of syringic acid and the metabolic products found in cultures of $S$. pulerulentum after various times of cultivation is given.

Phanerochaete sp. L-I metabolized syringic acid at a much slower rate than $S$. pulcerulentum (as determined by GC analysis) and no coloration appeared in the medium at any time during 

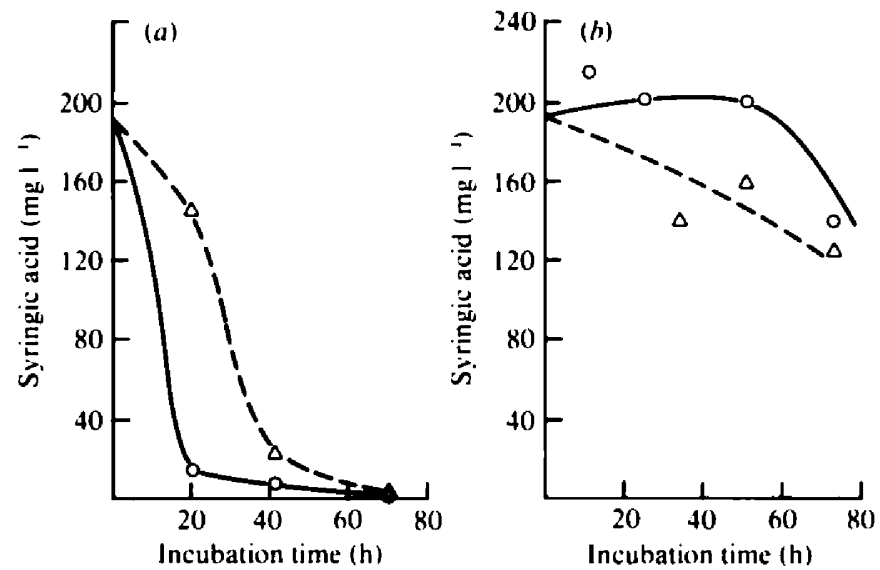

Fig. 1. Depletion of syringic acid in the culture medium by two white-rot fungi. (a) Sporotrichum pulcerulentum; (b) Phanerochaete sp. L-1. $\Delta$. With cellobiose: $O$, without cellobiose.<smiles>COc1cc(C(=O)O)cc(OC)c1O</smiles>

I<smiles>COc1cc(C(=O)O)cc(OC)c1OC</smiles>

11<smiles>COc1cc(CO)cc(OC)c1OC</smiles>

III<smiles>COc1cc(C(=O)O)cc(O)c1OC</smiles>

IV<smiles>COc1cc(C(=O)O)cc(O)c1O</smiles>

$\mathrm{v}$<smiles>COc1ccc(CO)cc1OC</smiles>

v।

Fig. 2. Compounds identified in culture medium of Sporotrichum pulcerulentum grown with syringic acid. Compound IV was identified by interpretation of MS data while the other metabolites were identified by GC, utilizing reference samples.

the cultivation. In contrast to $S$. pulcerulentum, the L-I fungus depleted the medium of the acid faster in the presence of cellobiose (Fig. $1 b$ ) than without cellobiose. No metabolite other than a small quantity of trimethoxybenzoic acid was found in the culture medium.

High phenol oxidase producers. In Pleurotus ostreatus cultures with added cellobiose, a dark brown coloration started to appear $8 \mathrm{~h}$ after syringic acid addition, due to high phenol oxidase 


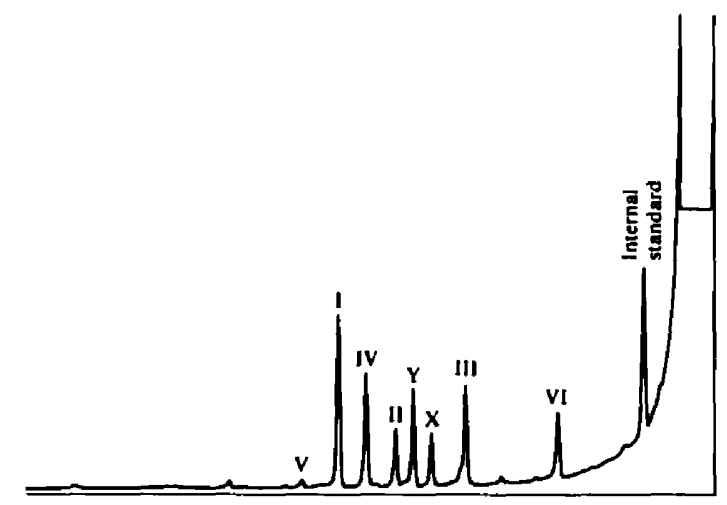

Fig. 3. Gas chromatographic separation of compounds in culture medium of Sporotrichum pulverulentum grown with syringic acid. $X$ and $Y$ are unidentified compounds (see text).
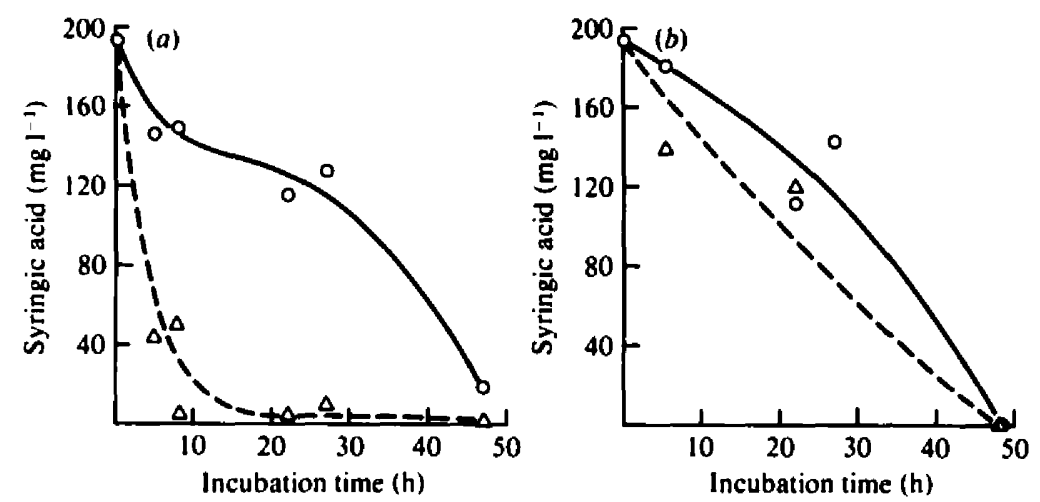

Fig. 4. Depletion of syringic acid in the culture medium by two white-rot fungi. (a) Pleurotus ostreatus; (b) Pycnoporus cinnabarinus. $\Delta$, With cellobiose; $O$, without cellobiose.

Table 1. Concentrations of identified compounds in culture solutions of Sporotrichum pulverulentum grown on syringic acid with $1 \%$ cellulose

Concentrations were determined by GC analysis.

\begin{tabular}{ccccccccc}
$\begin{array}{c}\text { Cultivation } \\
\text { time (h) }\end{array}$ & Compound $\ldots$ & \multicolumn{5}{c}{$\begin{array}{c}\text { Yield of identified compounds } \\
\text { (mol\% of original syringic acid): }\end{array}$} \\
\cline { 6 - 9 } 20 & & II & III & IV & V & VI \\
41 & & 3.5 & 2.4 & 1.0 & 2.2 & 0.09 & 0.2 \\
70 & & 2.0 & 1.3 & 0.9 & 1.4 & 0.15 & 0.89 \\
& & 0.4 & 1.3 & 0.1 & 0.5 & 0.17 & 0
\end{tabular}

production. The rapid depletion of syringic acid in the culture medium (Fig. $4 a$ ) is most probably due to polymerization reactions initiated by these enzymes. Trimethoxybenzoic acid and trimethoxybenzyl alcohol (II, III in Fig. 2) were found in small quantities. The brownish coloration appeared more slowly in cultures without cellobiose and hence depletion of the acid was also slower.

In Pycnoporus cinnabarinus cultures (Fig. 4 b), a pinkish coloration appeared as early as $3 \mathrm{~h}$ after syringic acid addition. After $26 \mathrm{~h}$ the colour changed to slightly brownish which was more 


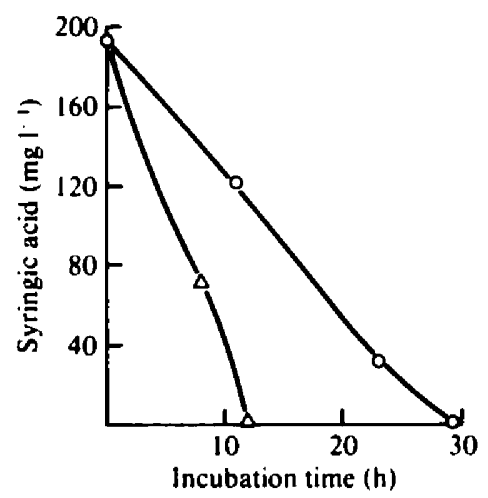

Fig. 5. Depletion of syringic and in the culture medium by two soft-rot fungi. $\Delta$, Petriellidium boydii; O. Phialophora mutabilis.

pronounced in cultures with cellobiose. In both cases, all the acid had disappeared after $47 \mathrm{~h}$. Traces of trimethoxybenzoic acid and the isomer of syringic acid 3-hydroxy-4,5-dimethoxybenzoic acid (IV) were identified in cultures without cellobiose. In cultures with cellobiose, trimethoxybenzoic acid, the isomer of syringic acid (IV), 3-O-methylgallic acid and one of the unidentified products in Fig. 3 were detected.

\section{Syringic acid metabolism by the two soft-rot fungi}

Both Petriellidium boydii and Phialophora mutabilis metabolized syringic acid rapidly (Fig. 5). In Petriellidium boydii cultures all the acid had disappeared within $12 \mathrm{~h}$ of addition. Traces of trimethoxybenzoic acid were found in both cases. No other metabolites were found in the cultures except for minor amounts of some unidentified product in Phialophora mutabilis cultures. At no time was any colour formation observed in cultures of the two soft-rot fungi.

Syringic acid metabolism by the two brown-rot fungi

Fomes pinicola and Daedalea quercina metabolized syringic acid slowly compared to the whiteand soft-rot fungi under the conditions used here. However, in cultures of $F$. pinicola 3-O-methylgallic acid was identified and after $190 \mathrm{~h}$ cultivation the yield of this compound was $6.6 \mathrm{~mol} \%$ of the original syringic acid. The transient appearance of a small quantity of an unidentified product was observed in cultures of $D$. quercina. However, these trace amounts completely disappeared at a later stage of the cultivation. In $F$. pinicola cultures the $\mathrm{pH}$ decreased to 2.8 after $148 \mathrm{~h}$ cultivation.

\section{DISCUSSION}

The available information on the ability of various wood-rotting fungi to degrade lignin shows that white-rot fungi can degrade this polymer more or less completely while brown-rot fungi bring about more limited alterations of the lignin molecule (Ander \& Eriksson, 1978; Crawford, 1981). According to Crawford (1981) the ability of the soft-rot fungi to degrade lignin is not clear although some of the existing evidence implicates a role for these fungi even as lignin degraders.

Syringyl (3,5-dimethoxy-4-hydroxyphenyl) structures mainly exist in hardwood lignins. A common feature in the metabolism of syringic acid by the white-rot and soft-rot fungi studied here is methylation of the $p$-hydroxyl group. One reason for this methylation could be detoxification of phenolics. It is thought that detoxification of phenolic compounds in white-rot fungi is mainly a function of phenol oxidases (Ander \& Eriksson, 1978). However, for soft-rot fungi, lacking phenol oxidases, the methylating capacity may serve this function. Therefore, it is interesting to note that both soft-rot fungi studied have the capacity to form trimethoxybenzoic acid from syringic acid via methylation of the p-hydroxyl group. To our knowledge this is the 


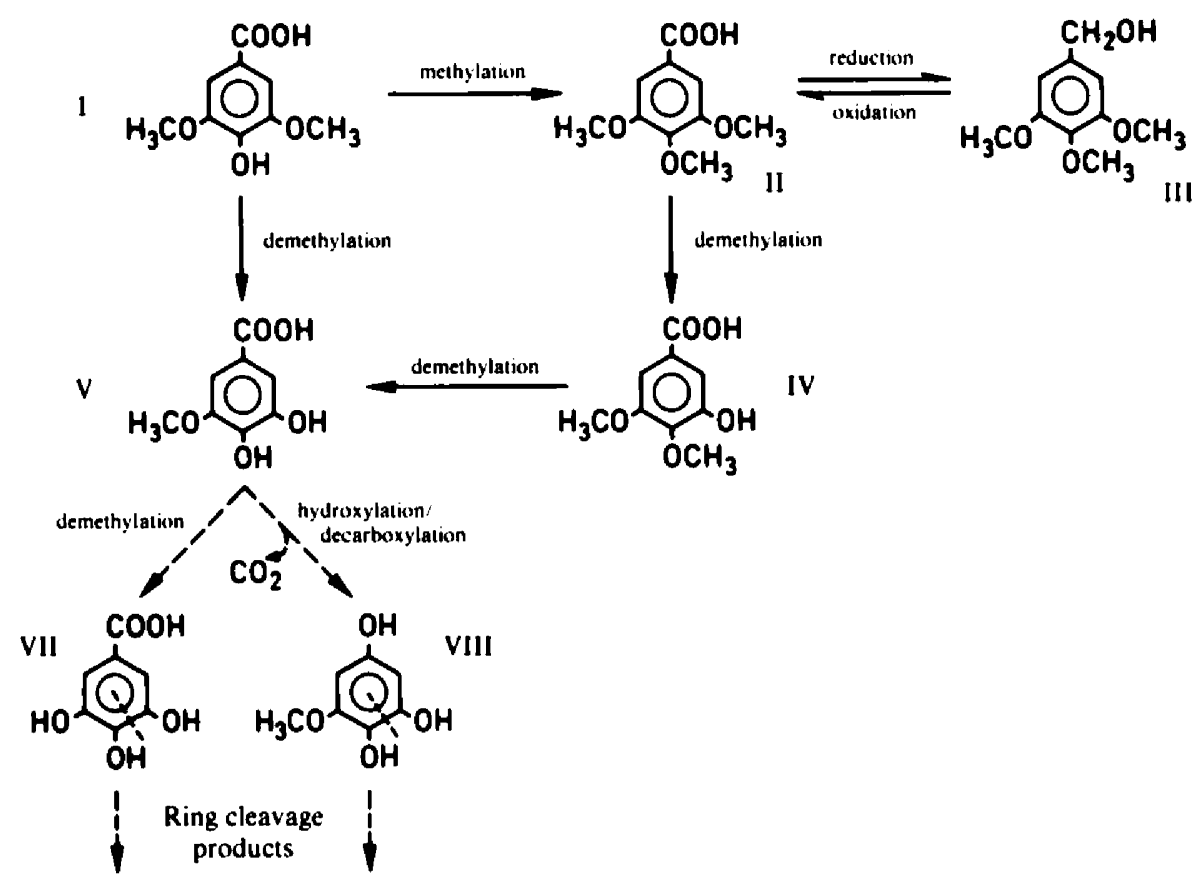

Fig. 6. Proposed reactions taking place during metabolism of syringic acid by Sporotrichum pulverulentum. Dashed lines indicate postulated metabolic pathways.

first report of such a reaction in soft-rot fungi. Indications of methylation by the white-rot fungus Phanerochaete chrysosporium have been given (Chen et al., 1982). In Sporotrichum pulverulentum the methylation of syringate is followed by reduction of the carboxyl group to trimethoxybenzyl alcohol. Similar reduction of the carboxyl group has been demonstrated previously during cultivation of S. pulverulentum on vanillic or ferulic acids (Ander et al., 1980; Gupta et al., 1981), but the role of this reduction has not yet been explained. However, it is increased in the presence of both glucose and cellobiose.

Cellobiose was used in this study mainly to stimulate growth of the brown-rot fungi which did not easily grow on cellulose as a sole carbon source. Addition of cellobiose to the white-rot cultures retarded the depletion of syringate in cultures of $S$. pulverulentum but stimulated the depletion in cultures of Phanerochaete sp. L-1, Pleurotus ostreatus and Pycnoporus cinnabarinus. It seems probable that the presence of cellobiose stimulates phenol oxidase production, at least in Pleurotus ostreatus.

It was found previously (Buswell et al., 1979) that $S$. pulverulentum hydroxylates/decarboxylates vanillic acid. Oxygen uptake was also observed in reaction mixtures of vanillate hydroxylase and syringic acid, although at a rate less than $10 \%$ of that for vanillic acid. Since decarboxylation of 3-O-methylgallate (V) by vanillate hydroxylase occurs at a high rate ( $75 \%$ of the rate observed with vanillic acid; Buswell et al., 1981), we believe that demethylation of syringate to produce 3-O-methylgallate is the first and main metabolic step in the degradation of syringate by $S$. pulverulentum (see Fig. 6). The product of demethylation of syringate has not been determined but demethylation of vanillate gives rise to methanol (Ander $e t$ al., 1983) probably via a quinone intermediate. This quinone is then immediately reduced. The white-rot fungus Schizophyllum commune degrades syringate with the formation of two methanol molecules to produce gallic acid (lyayi \& Dart, 1982).

Sporotrichum pulverulentum appears to have little or no ability to cleave the aromatic ring of catechol, protocatechuate and gentisate - well established ring fission substrates for bacterial dioxygenases. However, ring cleavage of hydroxyquinol (1,2,4-trihydroxybenzene), where three 
hydroxyl groups are present, does occur (Buswell \& Eriksson, 1979). Following demethylation of syringic acid into 3-O-methylgallic acid (demethoxylation followed by quinone reduction), the required third hydroxyl group for ring cleavage is thus easily introduced either by hydroxylation/decarboxylation or by another demethylation. Since in our experiments neither gallic acid (VII) nor 1,3,4-trihydroxy-5-methoxy benzene (VIII) was detected, it is not possible to evaluate which of these two compounds is ring-cleaved (Fig. 6).

Veratryl alcohol (VI) is known to be produced as a secondary metabolite in S. pulverulentum (Phanerochaete chry'sosporium) (Ander et al., 1980; Shimada et al., 1981). In this study veratryl alcohol was not synthesized de novo as has earlier been demonstrated (Lundquist \& Kirk, 1978; Ander $e t$ al., 1980). Veratryl alcohol could be identified in the culture medium only when syringic acid was present. Since it is not possible for us to explain how veratryl alcohol can be derived from syringic acid via known chains of metabolic events, it seems possible that the presence of syringic acid triggers secondary metabolism and hence de novo synthesis of veratryl alcohol.

The soft-rot fungi seem to transform lignin particularly by demethylation (Ander \& Eriksson, 1978; Crawford, 1981). Both Petriellidium boydii and Phialophora mutabilis metabolized syringic acid very rapidly. Apart from the small amounts of trimethoxybenzoic acid (III) no other intermediate was detected, suggesting a very rapid demethylation followed by immediate ring cleavage. These two fungi also evolved ${ }^{14} \mathrm{CO}_{2}$ from $\left[{ }^{14} \mathrm{C}\right]$ methoxyl-labelled syringic acid in high amounts (Ander et al., 1984). When vanillic acid metabolism by the same soft-rot fungi was studied, no intermediates were found in the culture solution (Buswell et al., 1982). A veratrate $O$ demethylase acting on both 3- and 4-positions has been described in the soft-rot fungus Chaetomium piluliferum by Paszczynski \& Trojanowski (1977).

The brown-rot fungi used in this study, Daedalea quercina and Fomes pinicola, proved to be poor degraders of syringic acid. However, the presence of 3-O-methylgallic acid in $F$. pinicola cultures clearly suggests some demethylating activity in this fungus. The decrease in the methoxyl content of lignin after attack by brown-rot fungi is well known (Crawford, 1981). The lignin in sweetgum wood (a hardwood) decayed by Lenzites trabea was demonstrated by Kirk \& Adler (1970) to have undergone demethylation. This effect was more pronounced in syringyl than in guaiacyl structures. Furthermore, Kirk (1975) also demonstrated that lignin containing syringyl structures decayed by the same fungus was extensively demethylated and contained 3,4dihydroxyphenyl moieties.

The results presented in this paper demonstrate that both white-rot and soft-rot fungi metabolize syringic acid very rapidly while brown-rot fungi are poor degraders of this compound.

\section{REFERENCES}

ADLER, E. (1977). Lignin chemistry - past, present and future. Wood Science and Technology 11, 169-218.

ANDER. P. \& ERIKSSON, K.-E. (1977). Selective degradation of wood components by white-rot fungi. Physiologia plantarum 41, 239-248.

Ander, P. \& Eriksson, K.-E. (1978). Lignin degradation and utilization by micro-organisms. Progress in Industrial Microbiology 14, 1-58.

Ander, P., Hatakka, A. \& Eriksson, K.-E. (1980). Vanillic acid metabolism by the white-rot fungus Sporotrichum pulverulentum. Archives of Microbiology 125, 189-202

Ander, P., Eriksson, K.-E. \& Yu, H.-s. (1983). Vanillic acid metabolism by Sporotrichum pulverulentum: evidence for demethoxylation before ringcleavage. Archives of Microbiology 136, 1-6.

ANDer, P., Eriksson, K.-E. \& YU, H.-s. (1984). Metabolism of lignin-derived aromatic acids by wood-rotting fungi. Journal of General Microbiology 130, 63-68.

Buswell, J. A. \& Erixsson, K.-E. (1979). Aromatic ring cleavage by the white-rot fungus Sporotrichum pulverulentum. FEBS Letters 104, 258-260

Buswell, J. A., Ander, P., Pettersson, B. \& ERIKsson, K.-E. (1979). Oxidative decarboxylation of vanillic acid by Sporotrichum pulverulentum. FEBS Letters 103, 98-101.

Buswell, J. A., Eriksson, K.-E. \& Pettersson, B. (1981). Purification and partial characterization of vanillate hydroxylase (decarboxylating) from Sporotrichum pulverulentum. Journal of Chromatography 215, 99-108.

Buswell, J. A., ERiksson, K.-E., Gupta, J. K., Hamp, S. G. \& NordH, I. (1982). Vanillic acid metabolism by selected soft-rot, brown-rot and white-rot fungi. Archives of Microbiology 131, 366-374. 
Chen, C.-L., Chang, H.-M. \& Kirk, T. K. (1982). Aromatic acids produced during degradation of lignin in spruce wood by Phanerochaete chrysosporium. Holzforschung 36, 3-9.

CRAWPORD, R. L. (1981). Lignin Degradation and Transformation. New York: John Wiley \& Sons.

Eriksson, K.-E. \& Pettersson, B. (1975). Extracellular enzyme system utilized by the fungus Sporotrichum pulverulentum (Chrysosporium lignorum) for the breakdown of cellulose. European Journal of Biochemistry 51, 193-206.

Gupta, J. K., HaMp, S. G., Buswell, J. A. \& Eriksson, K.-E. (1981). Metabolism of trans-ferulic acid by the white-rot fungus Sporotrichum pulverulentum. Archives of Microbiology 128, 349-354.

Haider, K. \& Trojanowski, J. (1975). Decomposition of specifically ${ }^{14} \mathrm{C}$-labelled phenols and dehydropolymers of coniferyl alcohol as models for lignin degradation by soft- and white-rot fungi. Archives of Microbiology 105, 33-41

Henderson, M. E. K. (1963). Fungal metabolism of certain aromatic compounds related to lignin. Pure and Applied Chemistry 7, 589-602.

IYAYI, C. B. \& DART, R. K. (1982). Degradation of sinapyl alcohol by the fungus Schizophyllum commune. Microbios 34, 167-176.

KiRK, T. K. (1975). Effects of a brown-rot fungus, Lenzites trabea, on lignin in spruce wood. Holzforschung 29. 99-107.

KIRK, T. K., \& ADLER, E. (1970). Methoxyl-deficient structural elements in lignin of sweetgum decayed by a brown-rot fungus. Acta chemica scandinavica 24, 3379-3390.

KiRx, T. K. L Lonenz, L. F. (1973). Methoxy hydroquinone, an intermediate of vanillate metabolism by Polyporus dichrous. Applied Microbiology 26, 173175.

KiRK. T. K. \& LORENZ, L. F. (1974). Oxygenation of 4 alkoxyl groups in alkoxybenzoic acids by Polyporus dichrous. Applied Microbiology 27, 360-367.

LUNDQUIST, K. \& KIRK. T. K. (1978). De noto synthesis and decomposition of veratryl alcohol by a lignindegrading basidiomycete. Phytochemistry 17, 1676.

Nimz, H. (1974). Birch lignin - proposal of a constitutional scheme. Angewandte Chemie 86, 336-344.

Paszczynski. A. \& Trojanowski. J. (1977). An affinity-column procedure for the purification of veratrate $O$-demethylase from fungi. Microbios 18 , III-121.

Shimada, M., Nakatsubo, F., Kirk, T. K. \& Higuchi, T. (1981). Biosynthesis of the secondary metabolite veratryl alcohol in relation to lignin degradation in Phanerochaete chrysosporium. Archives of Microbiology 129, 321-324.

Sparnins, V. L. \& Dagley, S. (1975). Alternative routes of aromatic catabolism in Pseudomonas acidonorans and Pseudomonas putida: gallic acid as a substrate and inhibitor of dioxygenases. Joumal of Bacteriology 124, 1374-1381. 